\title{
Acoustics and psychosocial environment in intensive coronary care
}

\section{Blomkvist, C A Eriksen, T Theorell, R Ulrich, G Rasmanis}

Occup Environ Med 2005;62:el (http://www.occenvmed.com/cgi/content/full/62/3/el). doi: 10.1136/oem.2004.017632

See end of article for authors' affiliations .....................

Correspondence to: Dr V Blomkvist Department of 'Public Health Care, Uppsala University, Sweden; vanja. blomkvist@pubcare.vu.se

Accepted

19 November 2004
Background: Stress, strain, and fatigue at the workplace have previously not been studied in relation to acoustic conditions.

Aims: To examine the influence of different acoustic conditions on the work environment and the staff in a coronary critical care unit (CCU).

Method: Psychosocial work environment data from start and end of each individual shift were obtained from three shifts (morning, afternoon, and night) for a one-week baseline period and for two four-week periods during which either sound reflecting or sound absorbing tiles were installed.

Results: Reverberation times and speech intelligibility improved during the study period when the ceiling tiles were changed from sound reflecting tiles to sound absorbing ones of identical appearance. Improved acoustics positively affected the work environment; the afternoon shift staff experienced significantly lower work demands and reported less pressure and strain.

Conclusions: Important gains in the psychosocial work environment of healthcare can be achieved by improving room acoustics. The study points to the importance of further research on possible effects of acoustics in healthcare on staff turnover, quality of patient care, and medical errors.
$\mathrm{T}$ he potential for evidence based design of healthcare physical environments to improve clinical and economic outcomes has attracted increasing attention as healthcare providers internationally have faced strong pressures to reduce costs yet increase care quality. Many studies show that the physical environment of healthcare facilities influences not only patient satisfaction but also outcomes such as pain and infection occurrence. ${ }^{1-5}$ However, few studies deal with effects of the physical design of healthcare on staff outcomes like job stress, work demands, fatigue, and quality of patient care. ${ }^{6}$ One research area illustrating this choice of focus is effects of noise in a hospital setting.

The need for research to inform the creation of better healthcare work spaces has never been greater or more time urgent. Several countries, including the United States and Britain, are embarking on vast programmes of healthcare building construction impelled by the aging of the populations and the technological obsolescence of older hospitals. The United States, for example, will spend more than \$16 billion for hospital construction in 2004, and this will increase to more than $\$ 20$ billion annually by $2010 .^{7}$ As a step towards addressing the urgent need for research on healthcare work spaces, the present study examined the influences of environmental acoustics on the psychosocial work environment in a coronary critical care unit (CCU) in a Swedish hospital.

Guideline values for continuous background noise in hospital wards are $30 \mathrm{~dB}$ LAeq, with night-time peaks at 40 $\mathrm{dB}$ LAmax. These guidelines further recommend that the continuous sound pressure level should not exceed $35 \mathrm{~dB}$ LAeq in patient rooms, including those in which patients are being treated. ${ }^{8}$ Guidelines notwithstanding, several studies have found that hospital background sound pressure levels typically fall in much higher ranges-45-68 db(A)-with peaks exceeding 85-90 db(A). ${ }^{9-11}$ Medical equipment and staff voices frequently produce $70 \mathrm{db}(\mathrm{A})$ sound levels measured at the patient's head, which approach decibel levels in a busy restaurant or urban street.
Most findings suggest that higher $\mathrm{db}(\mathrm{A})$ levels detrimentally affect at least some patient outcomes, for example, increasing heart rate and producing sleeplessness. ${ }^{10} 1213$

Even when decibel levels are kept relatively low (27-58 $\mathrm{db}(\mathrm{A})$ ), however, differences in acoustic properties with respect to reverberation times or echo/liveliness characteristics may be linked with variations in sleep quality as measured by EEG. In this regard, Berg ${ }^{14}$ found that volunteers evidenced improved sleep quality (less sleep fragmentation) when assigned to hospital patient rooms with shorter reverberation times (produced by sound absorbing ceiling tiles), in contrast to when assigned to rooms with longer reverberation times (sound reflecting tiles).

Studies concerning effects of noise on healthcare staff are scarce. There is some evidence that staff perceive higher sound levels in patient units as stressful. ${ }^{15}{ }^{16}$ Also, nurses' self-reports of noise induced stress correlate with selfreported emotional exhaustion. ${ }^{17}$ No previous research has addressed the focus of the present study-that is, the influence of differences in reverberation time on the psychosocial work environment. Many studies performed in laboratories and non-healthcare workplaces, ${ }^{18-20}$ however, have contributed to our knowledge of the effects of noise on stress and health, and have implications for research on acoustics and the psychosocial work environment in healthcare.

Noise is widely defined in the research literature as "unwanted sound", an interpretation that implies the importance of controllability and predictability in understanding the effects of sound on people. ${ }^{18-20}$ The emphasis on controllability means that whether or not sound is negative or stressful is largely a matter of psychology. For instance, detrimental psychological and physiological (heart rate, blood pressure, skin conductance, respiration rate) effects have been observed in laboratory studies when normal subjects are exposed to transient, uncontrollable sounds having intensity ranges comparable to those measured in certain healthcare settings (peak ranges of $75-85 \mathrm{~dB}(\mathrm{~A})) .{ }^{17}$ 


\section{Main messages}

- It seems likely that improved acoustic conditions reduce risks of conflicts and errors.

- Reverberation times and speech intelligibility improved during the study period when the ceiling tiles were changed from sound reflecting tiles to sound absorbing ones of identical appearance.

- For each individual shift the delta score was computed, indicating the accumulated effect of working conditions.

- Improved acoustics positively affected the work environment.

- Particularly during the afternoon shift the staff reported lower work demands and decreased pressure and strain.

- Important gains in the psychosocial environment of healthcare can be achieved by improving room acoustics.

Other laboratory research indicates that uncontrollable sounds that interfere with tasks or activities elicit negative changes in emotions. ${ }^{21}$

The psychological effects of noise may trigger behavioural aberration in healthy adults. Mental activities, such as sustained attention to multiple cues or complex analysis, are all directly sensitive to noise. Accidents may be indicators of noise related effects on performance. Thus, one critical effect of noise may be communication interference, including interference with warning signals. ${ }^{822} 23$

If the work organisation is bad with excessive demands combined with low decision latitude and poor support, sound reflecting acoustics (for example, excessive noise levels and long reverberation time) are likely to have more pronounced negative effects. ${ }^{25}$ One of the most widely used theoretical models in psychosocial environmental research is the demand control support model. ${ }^{24}$ It has been used for demonstrating that adverse combinations of high demands, low decision latitude (possibility for employees to exert control in the work situation) and poor social support from superiors and workmates give rise to physiological arousal reactions with energy mobilisation (resulting for instance in blood pressure elevation). Energy mobilisation is also followed by inhibition of regenerative activity in the body reflected for instance in decreasing blood concentration of anabolic hormones. If such physiological reactions are pronounced and long lasting they may increase illness risks. Demands, decision latitude, and social support are contingent on organisational factors, although the individual's perception also influences employee assessments. There are several epidemiological studies indicating that exposure to a combination of high psychological demands and low decision latitude increases the risk of developing myocardial infarction in working age even when adjustment for conventional risk factors has been made. ${ }^{26}$

Physiological correlates of job strain could be lowered as well as raised morning cortisol, raised IgE and interleukin 6 (both indicators of raised activity in the immune system), and disturbed blood pressure regulation. ${ }^{27} 28$ Studies have found connections between physical reactions such as musculoskeletal disorders and psychosocial environment, both due to the organisation and the relation to patients. ${ }^{29}$ Experiences of stress in intensive care units create conflicts for nurses, and the consequences may exceed the psychosocial and emotional resources of the staff. ${ }^{30}$

\section{Policy implications}

- There has been very little research on the influences of acoustics on healthcare staff.

- The study points at the importance of further research on possible effects of acoustics in healthcare on staff turnover, quality of care, and medical errors.

- The findings imply that an approach for improving healthcare acoustics will be inadequate if it focuses narrowly on reducing sound pressure levels.

The possibility of medical staff communicating effectively is potentially of great importance. When acoustic conditions are characterised by longer in contrast to shorter reverberation times, echoes (reverberant sounds) will cause blending and overlapping of sounds, thereby reducing speech intelligibility. ${ }^{31}$ Communication difficulties may also elicit irritation in staff, who may become less empathic to patients. ${ }^{32}$

The aim of this study was to explore the influence of room acoustics on the psychosocial work environment in coronary care. It was expected that an environmental condition of longer reverberation time would increase sound propagation and sound levels in the CCU, reduce speech intelligibility, and negatively affect the psychosocial environment. Conversely, it was expected that improved acoustics could lead to an improved perception of the work environment, with reduced feeling of load.

\section{STUDY GROUP AND METHODS}

\section{The medical setting}

Huddinge University Hospital has a catchment area of 375 000 inhabitants. The Department of Cardiology has a full service cardiac programme and serves as a referral clinic for two hospitals regarding angioplasty, electrophysiology, and thoracic surgery. The centre of the department is the coronary care unit (CCU) with eight beds, which is where the study took place (see fig 1). The comparatively small number of beds consequently enhances the turnover of patients in the unit; 6-7 patients with acute symptoms are daily admitted to the unit and the average observations time is 17 hours. Patients with unstable coronary heart disease are transferred after the initial observation period, to a step-down ward located beside the CCU. Patients with a less severe disease are transferred to a general cardiac ward of the opposite side of the CCU.

Both units are equipped with continuous ECG monitoring, all of which is controlled on screens in the CCU. All patients are monitored with a computerised system for ECG and/or haemodynamics, with different automatic alarms for critical values. Patients are continuously, when needed, transported to the laboratories for angiography, electrophysiology, or CT scanning. Laboratory testing is partly performed in a setting in a corner of the central area. This and other logistics, such as regular cleaning of the patient rooms, exchange of beds and laundry among other things, give the unit a noisy and somewhat turbulent atmosphere.

There were 31 patients ( 12 women) in the period of sound reflective ceilings and 44 ( 13 women) in the period of sound absorbing ceilings. Mean age in the sound reflective period was 67.45 years and was 67.52 years in the sound absorbing period. The patients' diagnoses and level of severity were comparable between the periods.

\section{Study group}

Nearly 50 nurses, all specially trained in cardiology, are employed at the unit, scheduled either for morning, 
Outdoors

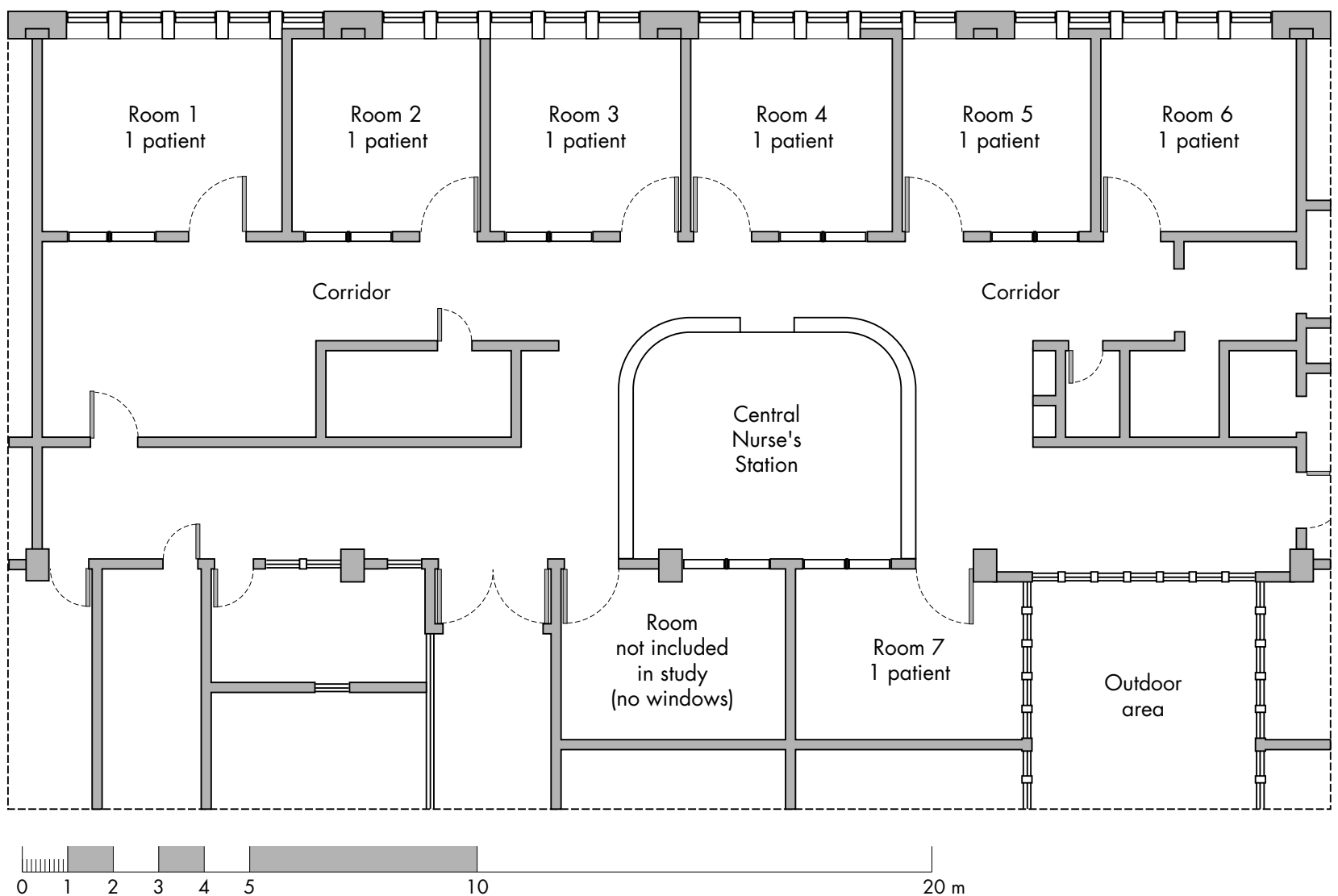

Figure 1 Floor plan of the CCU.

afternoon, or night shifts. The 36 nurses working regularly at the ward were asked to participate in the investigation of the psychosocial environment and emotional states at the start and end of each individual work shift. The members of the staff were informed of the changes and the aim of the project before the baseline study took place.

Twenty one nurses worked daytime and 15 worked nighttime shifts. Ages varied between 24 and 53 years (mean age 35 years). The daytime workers were scheduled either in a morning shift or an afternoon shift.

\section{Procedure}

After an initial baseline period the acoustics were changed in two steps in the patient rooms and the main work area of the unit where most decisions are made and monitoring of the patients takes place.

In the first step, remodelling of the ceiling took place, creating a sound reflective ceiling surface in the entire ward. In the second step, sound absorbing ceilings were installed throughout the ward.

The baseline period lasted for three weeks in November 2001. This period should be regarded as a "feasibility period" during which procedures and questionnaires were tested. The first part of the main study (sound reflecting period) was carried out during 20 weekdays-from the beginning of February until the beginning of March 2002. The second part (sound absorbing period) lasted from March during 22 weekdays until the middle of April 2001. Data for the project were collected during regular weekdays and corresponding nights, but not during weekends since there were changes in staffing and conditions during such periods. To promote candour and validity when filling out the questionnaire, each nurse received a numerical ID which was used instead of their names.

Questionnaires with psychosocial items were distributed and filled out on two occasions during the shift-at the beginning of the work shift and at the very end. The questions describing work situation were pace of work (high or low tempo), quantity of work (great or small), decision latitude (high or low), own competence (high or low), own hard decisions ( seldom or often), self-determination (a lot or a little), information/education (a lot or a little), atmosphere at work (calm or unsettling), quality of care (easy to prioritise or hard to prioritise), and social support at work (good or poor). These questions correspond roughly to a condensed visual analogue version of the demand-control-support model, Swedish version. ${ }^{30}$ The questions describing mood states were hastiness, calmness, irritation, anxiety, tension, happiness, sadness, anger, depression, stress, and fatigue. A longer version of this selection of adjectives has been used in previous research. ${ }^{34}$ Analyses were performed with the difference between "end" and "start" score ("delta" values). The rationale behind the analysis of the delta values was that the accumulated effect of the exposure of working conditions would be particularly visible in the comparison between the start and the end levels. Another way of expressing this is that the delta value shows the "netto" effect. A negative delta score indicates a lower score at the end of the shift than at the beginning.

All psychosocial questions were measured with visual analogue scales.

A 1 decimeter horizontal line corresponded to each item. The ends had verbal anchors (low and high extremes) and there were no intermediate levels marked on the line. The 
participant was asked to make a cross on the line at the level that corresponded to the current condition. The distance in $\mathrm{mm}$ from 0 to the cross was measured. In the statistical analysis the measures were used as scores from 0 to 10. Statistically, the results obtained with the visual analogue scales were comparable to those obtained with the original questionnaires which were constructed with ordinal scales. $^{33-35}$

The participants were aware of the nature of the manipulations. It would not have been possible to "blind" them to the purpose of the study.

\section{Acoustic materials and methods}

Acoustic measurements were done in the main work area and in three patient rooms. The reverberation time was the major acoustic variable defined as the time needed for the sound pressure level to decrease by $60 \mathrm{~dB}$ after the sound source has been switched off. A change in reverberation time was expected to influence sound pressure level, sound propagation, and speech intelligibility of the premises. The reverberation time was measured for the two different conditions $^{36}$ in the main work area and in Room 4. Patient rooms 1-7 were judged as similar in terms of room acoustic character (size, height, and positioning of furniture and equipment, etc) which meant that measurements were limited to Room 4. The equivalent sound pressure level (LAeq) was measured for one week during each study period in Rooms 1, 4, and 7 (see fig 1) and in the main work area of the ward. Sound propagation was determined by measuring the attenuation of a reference sound of $88 \mathrm{db}(\mathrm{A})$ pink noise (positioned in the lower corner of the left corridor), which was louder than the background noise level at all measured positions. Measurements were done at predetermined intervals from the source along the outer wall of the main ward..$^{37-39}$ The sound pressure level of the reference sound was also measured in two patient rooms situated along the outer wall. Speech intelligibility was measured according to the RASTI (Rapid Speech Transmission Index) method, ${ }^{40}$ and intended to measure the effects on speech caused by background noise (mechanical installations and equipment) and reverberant sound. Measurements were done in Room 4 (the speaker next to the bed and the receiver at the patient's head) as well as at two positions in the main work area. The speaker was positioned at the lower left corner of the central nursing station and the receiver was positioned either at the upper right corner of the station or at the entrance to Room 5. The RASTI method allows the user to transform the numeric values to a qualitative interpretation, ranging from "bad", "poor", "fair", "good", to "excellent".

One of the patient rooms was not in use during the two study periods and therefore no acoustic analysis was performed.

\section{Acoustic manipulation/experimentation}

Reverberation time was manipulated during the two study periods through the use of sound reflective and sound absorbing ceilings. A sound reflective suspended ceiling ( $13 \mathrm{~mm}$ solid painted plaster board tiles) was mounted in the main work area. The original ceiling tiles $(25 \mathrm{~mm}$ thick resin bonded glass wool with a painted surface) in the main work area were judged to correspond to absorption class A. ${ }^{41}{ }^{42}$ The patient rooms already contained a reflective ceiling surface (solid painted plaster). During the fifth week the plaster ceiling tiles in the main work area were substituted by

Table 1 Delta (end of shift minus start) sum scores based on principal component analysis

\begin{tabular}{|c|c|c|c|c|c|c|c|c|}
\hline & & Baseline (B) & $\begin{array}{l}\text { Sound reflecting } \\
\text { (SR) }\end{array}$ & $\begin{array}{l}\text { Sound absorbing } \\
\text { (SA) }\end{array}$ & F value & $\begin{array}{l}\text { B-SR } \\
\text { Post hoc p }\end{array}$ & $\begin{array}{l}\text { B-SA } \\
\text { Post hoc } p\end{array}$ & $\begin{array}{l}\text { SR-SA } \\
\text { Post hoc p }\end{array}$ \\
\hline Morning shift & & $n=13$ & $\mathrm{n}=94$ & $n=70$ & & & & \\
\hline Demand & $\begin{array}{l}M / S D \\
95 \% \mathrm{Cl}\end{array}$ & $\begin{array}{l}-1.15 / 2.91 \\
-2.74 \text { to } 0.43\end{array}$ & $\begin{array}{l}0.78 / 2.71 \\
0.23 \text { to } 1.33\end{array}$ & $\begin{array}{l}0.65 / 2.26 \\
0.12 \text { to } 1.18\end{array}$ & 3.31 & 0.011 & 0.021 & 0.739 \\
\hline Control/supp & $\begin{array}{l}\mathrm{M} / \mathrm{SD} \\
95 \% \mathrm{Cl}\end{array}$ & $\begin{array}{l}-0.67 / 1.55 \\
-1.51 \text { to } 0.17\end{array}$ & $\begin{array}{l}-0.38 / 1.58 \\
-0.70 \text { to }-0.07\end{array}$ & $\begin{array}{l}-0.82 / 1.51 \\
-1.17 \text { to }-0.46\end{array}$ & 1.60 & 0.527 & 0.761 & 0.078 \\
\hline Distress & $\begin{array}{l}\mathrm{M} / \mathrm{SD} \\
95 \% \mathrm{Cl}\end{array}$ & & $\begin{array}{l}0.06 / 1.18 \\
-1.18 \text { to } 0.29\end{array}$ & $\begin{array}{l}0.03 / 0.91 \\
-0.19 \text { to } 0.24\end{array}$ & 0.71 & & & 0.868 \\
\hline Pressure & $\begin{array}{l}\mathrm{M} / \mathrm{SD} \\
95 \% \mathrm{Cl}\end{array}$ & & $\begin{array}{l}1.48 / 2.77 \\
0.92 \text { to } 2.04\end{array}$ & $\begin{array}{l}1.34 / 2.83 \\
0.68 \text { to } 2.01\end{array}$ & 9.42 & & & 0.758 \\
\hline Strain & $\begin{array}{l}\mathrm{M} / \mathrm{SD} \\
95 \% \mathrm{Cl}\end{array}$ & & $\begin{array}{l}0.62 / 1.87 \\
0.24 \text { to } 0.99\end{array}$ & $\begin{array}{l}0.25 / 1.34 \\
-0.06 \text { to } 0.57\end{array}$ & 2.58 & & & 0.171 \\
\hline Afternoon shift & & $\mathrm{n}=18$ & $\mathrm{n}=53$ & $\mathrm{n}=36$ & & & & \\
\hline Demand & $\begin{array}{l}\mathrm{M} / \mathrm{SD} \\
95 \% \mathrm{Cl}\end{array}$ & $\begin{array}{l}-0.55 / 3.09 \\
-1.98 \text { to } 0.88\end{array}$ & $\begin{array}{l}0.26 / 2.86 \\
-0.51 \text { to } 1.03\end{array}$ & $\begin{array}{l}-2.16 / 2.30 \\
-2.91 \text { to }-1.41\end{array}$ & 8.47 & 0.282 & 0.043 & 0.0001 \\
\hline Control/supp & $\begin{array}{l}\mathrm{M} / \mathrm{SD} \\
95 \% \mathrm{Cl}\end{array}$ & $\begin{array}{l}-1.16 / 1.60 \\
-1.90 \text { to }-0.42\end{array}$ & $\begin{array}{l}-0.98 / 2.04 \\
-1.53 \text { to }-0.43\end{array}$ & $\begin{array}{l}-0.89 / 1.82 \\
-1.49 \text { to }-0.30\end{array}$ & 0.12 & 0.730 & 0.632 & 0.837 \\
\hline Distress & $\begin{array}{l}\mathrm{M} / \mathrm{SD} \\
95 \% \mathrm{Cl}\end{array}$ & & $\begin{array}{l}-0.05 / 1.15 \\
-0.36 \text { to } 0.26\end{array}$ & $\begin{array}{l}-0.39 / 0.88 \\
-0.68 \text { to }-0.10\end{array}$ & 1.87 & & & 0.116 \\
\hline Pressure & $\begin{array}{l}\mathrm{M} / \mathrm{SD} \\
95 \% \mathrm{Cl}\end{array}$ & & $\begin{array}{l}0.25 / 3.17 \\
-0.60 \text { to } 1.11\end{array}$ & $\begin{array}{l}-1.73 / 2.29 \\
-2.48 \text { to }-0.98\end{array}$ & 4.96 & & & 0.003 \\
\hline Strain & $\begin{array}{l}\mathrm{M} / \mathrm{SD} \\
95 \% \mathrm{Cl}\end{array}$ & & $\begin{array}{l}0.08 / 2.02 \\
-0.46 \text { to } 0.63\end{array}$ & $\begin{array}{l}-0.85 / 1.88 \\
-1.47 \text { to }-0.24\end{array}$ & 2.45 & & & 0.029 \\
\hline Night shift & & $n=46$ & $\mathrm{n}=53$ & $\mathrm{n}=37$ & & & & \\
\hline Demand & $\begin{array}{l}M / S D \\
95 \% \mathrm{Cl}\end{array}$ & $\begin{array}{l}1.52 / 2.52 \\
0.79 \text { to } 2.25\end{array}$ & $\begin{array}{l}1.26 / 2.57 \\
0.57 \text { to } 1.95\end{array}$ & $\begin{array}{l}1.23 / 2.36 \\
0.47 \text { to } 1.99\end{array}$ & 0.18 & 0.611 & 0.601 & 0.953 \\
\hline Control/supp & $\begin{array}{l}\mathrm{M} / \mathrm{SD} \\
95 \% \mathrm{Cl}\end{array}$ & $\begin{array}{l}0.18 / 1.46 \\
-0.24 \text { to } 0.60\end{array}$ & $\begin{array}{l}0.20 / 1.31 \\
-0.15 \text { to } 0.56\end{array}$ & $\begin{array}{l}0.29 / 0.81 \\
0.03 \text { to } 0.55\end{array}$ & 0.09 & 0.932 & 0.692 & 0.742 \\
\hline Distress & $\begin{array}{l}\mathrm{M} / \mathrm{SD} \\
95 \% \mathrm{Cl}\end{array}$ & & $\begin{array}{l}0.16 / 0.89 \\
-0.08 \text { to } 0.40\end{array}$ & $\begin{array}{l}0.17 / 1.63 \\
-0.35 \text { to } 0.70\end{array}$ & 1.36 & & & 0.957 \\
\hline Pressure & $\begin{array}{l}M / S D \\
95 \% \mathrm{Cl}\end{array}$ & & $\begin{array}{l}1.49 / 2.64 \\
0.78 \text { to } 2.20\end{array}$ & $\begin{array}{l}1.32 / 2.44 \\
0.53 \text { to } 2.11\end{array}$ & 0.20 & & & 0.785 \\
\hline Strain & $\begin{array}{l}\mathrm{M} / \mathrm{SD} \\
95 \% \mathrm{Cl}\end{array}$ & & $\begin{array}{l}0.25 / 1.37 \\
-0.12 \text { to } 0.62\end{array}$ & $\begin{array}{l}0.04 / 1.98 \\
-0.60 \text { to } 0.67\end{array}$ & 1.24 & & & 0.585 \\
\hline
\end{tabular}

Results expressed as number of observations, means (M)/standard deviations (SD), 95\% confidence limits of means $(\mathrm{Cl})$, and results of one way analyses of variance. Post hoc $\mathrm{p}$ values for analyses with three conditions (Fisher's PLSD). 
visually identical sound absorbing ceiling tiles. Additionally the eight patient rooms were fitted with the same type of sound absorbing ceiling tiles.

The sound absorbing Ecophon ceiling tile is made from a $40 \mathrm{~mm}$ thick high density resin bonded glass wool with a painted surface. The ceiling tiles have high sound absorption, absorption class A. ${ }^{41}{ }^{42}$

\section{Statistical methods}

A principal component analysis (varimax, roots $>1$ ) highlighted a demand factor (high pace of work, high quantity of work, bad atmosphere at work, high demand on quality of care) as well as a control/support factor (autonomy, selfdetermination, own competence, social support at work), which corresponds roughly to a combined decision latitude and social support factor in the demand-control-support model. ${ }^{11}$ The mood scales were also submitted to principal component analysis. Three distinct factors were found, namely distress (anxiety, sadness, depression), pressure (stress, calmness (reversed), hastiness), and strain (irritation, anger, tension). Five indices were computed by means of the summation of item scores within each dimension (demand, control/support, distress, pressure, strain). For each individual work shift the "delta" score (sum score at end minus sum score at start of shift) was computed, indicating the accumulated effect of working conditions. Means and 95\% confidence intervals of these means were calculated for all the five sum delta scores during baseline, sound reflecting, and sound absorbing conditions. The calculations were made separately for the morning, afternoon, and night shifts. One way analyses of variance were made separately for morning, afternoon, and night shifts, with post hoc tests (Fisher's PLSD) comparing baseline-sound reflecting, baseline-sound absorbing, and sound reflecting-sound absorbing conditions. For the three mood scales complete information was not available for the baseline period. For these scales, the only possible comparison was between the sound reflecting and sound absorbing periods.

Finally, five two-way analyses of variance (MANOVA) were performed using shift and acoustic condition (sound reflecting versus sound absorbing) as explanatory and each one of the five delta sum scores as dependent variables.

This study was approved by the local research ethics committee of Huddinge University Hospital, Stockholm, Sweden.

\section{RESULTS}

\section{Drop out and participation}

In order to avoid measurement instability, we only asked regularly-not temporarily-working staff to fill out the questionnaires.

The sound reflecting period lasted for 20 days which corresponded to a maximum of 300 possible shifts. Two hundred of these shifts $(67 \%)$ were covered by start and end questionnaires. Accordingly the total percentage of lost shifts was $33 \%$. Sixteen per cent of the lost shifts were due to planned education, $8 \%$ to vacation, and $8 \%$ to sick leave due to own or child's illness. Only three ( $1 \%)$ were "true" dropouts in the sense that there was no satisfactory explanation of the loss.

During the sound absorbing observation period that lasted for 22 days the maximum possible number of shifts was 330 . One hundred and forty two (43\%) were covered by start and end questionnaires. Accordingly the total percentage of lost shifts was $57 \%$. Thirty seven per cent of these were due to planned education, vacation, and sick leave due to own or child's illness (with relative proportions as in the previous period). The higher percentage of such drop-outs was mainly due to a vacation week (Easter). In addition, along the same lines as in the previous period, 20\% were "true" drop-outs.

For the baseline period no corresponding calculations could be performed since the data collection was not continuous.

\section{Psychosocial environment}

Number of observations, means, standard deviations, and 95\% confidence intervals for the three periods are presented separately in table 1 together with results of one-way analyses of variance.

There was a significant worsening of delta demands from the baseline period to both experimental periods (regardless of acoustic conditions) during the morning shift. During the afternoon shift, delta demands were perceived as significantly improved (lowered) from the baseline to the sound absorbing period. During the night shift there were no period differences.

Prominent differences with regard to the delta values were found in the afternoon shift when comparing the sound reflecting and the sound absorbing condition. There was a highly significant improvement in demand ("delta") $(p=0.0001)$. Separate item analyses showed that improvements in pace of work, quantity of work, atmosphere at work, and demands on quality of work all contributed to this. There were also significant improvements with regard to "pressure" $($ "delta") $\quad(\mathrm{p}=0.0003)$ and "strain" ("delta") $\quad(\mathrm{p}=0.029)$ during the afternoon shift. Separate item analyses showed that changes in "lack of calmness", "hastiness", and "stress" ("delta") all contributed to the improvement in "pressure" ("delta") and that changes in "tension" and "irritation" ("delta") contributed to the improvement in "strain".

Two-way analyses of variance (table 2 ) showed significant main effects of acoustic conditions for delta demand, delta pressure, and delta strain. In this table the baseline condition was not included. There were significant two-way interactions (shift and acoustics) for delta demand and delta pressure. This means that the effects of the acoustics were significantly different in the three shifts for these variables. No interaction, however, was found for delta strain. This means that the effects of the acoustics on delta strain were similar in the three shifts.

The delta index demand was chosen to illustrate the changes over time for the afternoon shifts (see fig 2).

Table 2 Two-way analysis of variance with reflecting/ absorbing acoustics and shift as explanatory and the five delta sum variables as dependent variables

\begin{tabular}{lrl}
\hline & $\mathbf{F}$ value & $\mathbf{p}$ \\
\hline Delta demand & & \\
$\quad$ Sound reflecting/absorbing & 8.78 & 0.003 \\
$\quad$ Shiff & 18.03 & 0.0001 \\
$\quad$ Interaction & 6.63 & 0.002 \\
Control/supp & & \\
$\quad$ Sound reflecting/absorbing & 0.23 & 0.630 \\
$\quad$ Shiff & 13.43 & 0.0001 \\
$\quad$ Interaction & 1.14 & 0.323 \\
Distress & & \\
$\quad$ Sound reflecting/absorbing & 0.87 & 0.352 \\
$\quad$ Shiff & 2.70 & 0.069 \\
$\quad$ Interaction & 0.70 & 0.496 \\
Pressure & & \\
$\quad$ Sound reflecting/absorbing & 5.89 & 0.016 \\
$\quad$ Shiff & 19.46 & 0.0001 \\
$\quad$ Interaction & 3.54 & 0.030 \\
Strain & & \\
$\quad$ Sound reflecting/absorbing & 6.43 & 0.012 \\
Shiff & 6.19 & 0.002 \\
Interaction & 1.07 & 0.344 \\
\hline & & \\
\hline
\end{tabular}




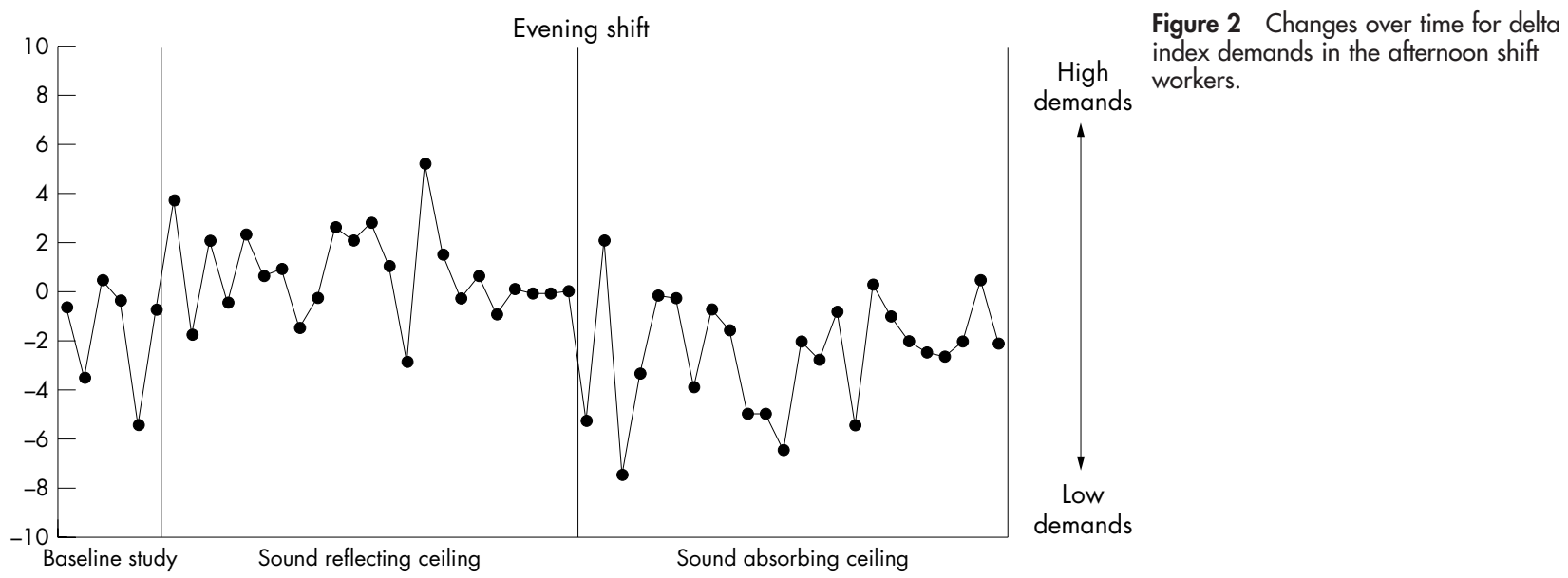

The figure shows changes over time in delta demands from the baseline study, period of sound reflecting ceilings, and the period of sound absorbing ceilings. More ratings were collected during the sound reflecting and sound absorbing periods. However, the figure clearly illustrates differences over time between the three different study periods.

\section{Acoustic environment}

The acoustic measurements (equivalent sound pressure level) were continuous for one week during each study period (table 3 ). Reverberation time improved from 0.8 to 0.4 seconds after the instalment of the sound absorbing ceiling in the main working area, and from 0.9 to 0.4 seconds in one of the patient rooms. The sound pressure level measured directly over the main work area did not vary greatly during the two weeks $(57 v 56 \mathrm{db}(\mathrm{A}))$. As the microphone was positioned directly over the work area, mainly direct sound was measured, and under such circumstances changes in reverberation time have little impact on sound pressure level.

The measurements confirm that the central area was the noisiest area in the ward. The two patient rooms (4 and 7) showed a drop in sound level of 5-6 dB, where ca $3 \mathrm{~dB}$ is due to the shorter reverberation time in the actual room and 2-3 $\mathrm{dB}$ is due to a lower sound pressure level in the ward. This is also confirmed by the sound propagation measurements (see table 4).

The effect of the reference sound in the two rooms, Rooms 1 and 4 respectively, was 75 and $64 \mathrm{db}(\mathrm{A})$ during the first period and 69 and $59 \mathrm{db}(\mathrm{A})$ during the second period. For the two periods, speech intelligibility (RASTI value), improved from "good" to "excellent" in both measured areas.

\section{DISCUSSION}

The findings indicate that the improved acoustics had affected the psychosocial environment in such a way that during the afternoon the staff experienced reduced demands, and less pressure/strain. Such changes open up for an increased capacity to care for the patients.

It seems likely that improved acoustic conditions in the healthcare environment reduce risks of conflicts and errors. During the study period with the sound absorbing acoustics the staff reported that they also felt more relaxed and irritability decreased. Although there were fewer patients during the period with poor acoustics (longer reverberation time), the staff experienced more strain, demands and pressure at work. These negative effects occurred despite the fact that the nurses were highly educated, well trained in acute situations, and accustomed to coping with high demands and making critical decisions.

The staff members were surprised by the improved speech intelligibility after the installation of the new ceiling as well as the perceived noise level. During the period of long reverberation time speech intelligibility was thought to be below what is needed in the CCU. It is possible that alternative wording should be developed to better reflect the demands on speech intelligibility in this type of work environment. Although long term measurements have been unable to fully confirm this, the findings together suggest that the staff experienced a reduced noise load during the working day when sound absorbing ceiling tiles were in place. The most prominent positive effects of improved acoustics on the psychosocial work environment were found for the afternoon shift. Most of the effects were observed during the afternoon shift. This was also the shift that was subjected to the most noise due to family visits. In addition,

Table 3 Sound reflecting ceilings vs. sound absorbing ceilings; acoustic measurements in three areas of the ward (reverberation time, sound pressure level, and speech intelligibility)

\begin{tabular}{|c|c|c|c|c|c|c|}
\hline \multirow[b]{2}{*}{ Area } & \multicolumn{2}{|c|}{ Reverberation time (s) } & \multicolumn{2}{|c|}{$\begin{array}{l}\text { Equivalent sound pressure } \\
\text { level }\left(L_{\text {Aeq }}\right)\end{array}$} & \multicolumn{2}{|c|}{ Speech intelligibility (RASTI value) } \\
\hline & $\begin{array}{l}\text { Sound } \\
\text { reflecting }\end{array}$ & $\begin{array}{l}\text { Sound } \\
\text { absorbing }\end{array}$ & $\begin{array}{l}\text { Sound } \\
\text { reflecting }\end{array}$ & $\begin{array}{l}\text { Sound } \\
\text { absorbing }\end{array}$ & $\begin{array}{l}\text { Sound } \\
\text { reflecting }\end{array}$ & $\begin{array}{l}\text { Sound } \\
\text { absorbing }\end{array}$ \\
\hline Central area & 0.8 & 0.4 & 57 & 56 & $0.72 / 0.68^{*}$ & $0.88 / 0.83^{*}$ \\
\hline Patient room 4 & 0.9 & 0.4 & 56 & 50 & 0.67 & 0.87 \\
\hline Patient room 7 & - & - & 56 & 51 & - & - \\
\hline
\end{tabular}

-, not measured.

*Measurements performed in two different positions. 
Table 4 Sound propagation; attenuation of the reference sound (pink noise $88 \mathrm{db}(\mathrm{A})$ 1 metre from the source) at predetermined intervals from the source

\begin{tabular}{lllllll}
\hline & \multicolumn{7}{l}{ Distance from the source $(\mathbf{m})$} \\
\cline { 2 - 7 } & $\mathbf{2}$ & $\mathbf{6}$ & $\mathbf{1 0}$ & $\mathbf{1 4}$ & $\mathbf{1 8}$ & $\mathbf{2 2}$ \\
\hline Sound reflecting $\mathrm{L}_{\text {Aeq }}(\mathrm{dB})$ & 83 & 80 & 78 & 75 & 72 & 70 \\
Sound absorbing $\mathrm{L}_{\text {Aeq }}(\mathrm{dB})$ & 82 & 76 & 72 & 70 & 65 & 64 \\
\hline
\end{tabular}

the morning shift overlapped with, or worked parallel to, the afternoon shift during the initial part of the afternoon.

There was a significant worsening of delta demand between the baseline period and the period with the sound absorbing acoustics, perhaps partly due to some disarray still present during the first weeks of installation of the sound absorbing ceiling.

It is important to raise the question of a possible Hawthorne effect. Almost any change or extra attention, or the knowledge that a study is being conducted, can be enough to cause subjects to change. In this study design, however, the extra attention experienced by the staff was constant throughout the periods of sound reflecting and sound absorbing acoustics. Further, the patterns of improvement and deterioration observed were stable throughout the two periods. A Hawthorne effect would have resulted in an attenuation of the beneficial effect of sound absorption (shorter reverberation time) during the studied one month period, and perhaps in a progressive worsening of the perceived work environment during the sound reflective period (longer reverberation time). Control/support and distress were not affected by the acoustic condition at all. It is unlikely that the physical change and disarray associated with modification of the CCU ceiling at the start could explain the difference.

Testing of the possible statistical significance of differences between the acoustic conditions was based on the following considerations. A large number of observations were made. The number of staff was relatively small, on the other hand. "Losses" of observations in individual participants were of course very natural since every person could not work three shifts every day. Natural losses of observations were made because of illness episodes, periods of part time work, etc, and in addition there were changes in shift work schedules. Because of these non-systematic losses we decided to regard every observation, regardless of individual, as an independent observation. This decision was supported by the fact that shifts in the coronary care unit could be very different; one shift may have a large influx of severely ill newly admitted patients while the next shift may have almost no patients, etc. Shortage of staff, which has a pronounced influence on perceived load, also occurs randomly.

It was therefore felt that differences in individual perception may play a relatively small role compared to the situations in which the work environment is being studied-in which differences in real conditions may be more important, particularly for load and demand measures. An important condition for this decision is that there was a comparable mix of individuals and observations between the three study periods. This condition was fulfilled.

That every observation was regarded as an independent one may have influenced the statistical significance levels in some of the analyses. These effects are likely to be marginally in the direction of "improved" $p$ values. A cautionary procedure could accordingly be to regard all findings that are significant on the $5 \%$ level as uncertain. In the comparison between the sound reflecting and sound absorbing period during the afternoon shift this pertains only to one of three significant findings $(p=0.029)$ out of five tests altogetherthe remaining two findings in this column are significant at least on the $1 \%$ level.

The decision to regard each observation as an independent one was supported by an analysis of autocorrelations based on the six subjects who had at least five observations regarding change in demands (end minus start score in a shift), in both the good and the bad acoustics condition respectively. These autocorrelations were tested with different lags (one to four observations) and turned out to be zero to modest and randomly distributed (mean $-0.11,15 / 24$ being between -0.30 and 0.30 and the extremes being -0.57 to 0.41 ). Thus there was no strong linear within-subject dependence for this main variable.

When the staff member is arriving to start a shift she will immediately see how many patients there are in the ward and what the atmosphere looks like. If the load and/or intensity increases during the shift this will be reflected in increased load scores. Mood states will be sensitive to changes in the same way. Accumulated effects of increasing load will be of particular importance. When the participant starts working in the morning shift she may be tired and feel gloomy because of the early morning hour. As she becomes active the normal circadian variation in mood makes her feel more active and perhaps happy. This introduces a possible source of error in the work environment assessments and may partly explain why the afternoon shifts (which may be relatively unaffected by this particular factor) are the ones that differ most clearly between the two acoustics periods. It may also explain why there are differences between the shifts.

There has been very little published research on the influences of acoustics on healthcare staff, although there are some previous examples. A recent study ${ }^{43}$ of staff in a paediatric intensive ward showed correlations between sound level and indicators of perceived stress. The low number of previous research reports has hindered the development of evidence based design and construction of guidelines or standards for CCUs and other healthcare settings. Although the sound reflecting ceiling condition (longer reverberation time), compared to the sound absorbing condition, detrimentally affected the CCU work environment, the sound reflecting ceiling nonetheless complied with healthcare building requirements or standards in Sweden and many other countries.

The study clearly raises the possibility that important gains in the psychosocial work environment of healthcare can be achieved by improving environmental acoustics. The findings imply that an approach for improving healthcare acoustics will be inadequate, however, if it focuses narrowly on reducing sound pressure levels.

Rather, a more effective approach will additionally emphasise environmental design interventions that shorten reverberation time. The importance of improved environmental acoustics for influencing speech intelligibility and perceived work demands, point to the need for further research to examine the possible role of acoustics in medical errors and other aspects of patient safety. 


\section{ACKNOWLEDGEMENTS}

This study was partly funded by Ecophon under the supervision of Jasper Cole, BSc and Sören Berg, MD, PhD. Acoustic measurements have been performed by Ingemansson Technology $\mathrm{AB}$, under the supervision of Leif Åkerlöf (MSc), Gunilla Sundin (MSc), and Peter Petterson (BSc). They have also given valuable input in the formulation of the acoustic measurements as well as the final article. A grant to Dr Theorell from the Swedish Council for Work Environment Research (RALF) also contributed to the study.

\section{Authors' affiliations}

V Blomkvist, C A Eriksen, T Theorell, National Institute for Psychosocial Factors and Health, Stockholm, Sweden

R Ulrich, Center for Health Systems and Design, Texas A\&M University, College Station, Texas, USA

G Rasmanis, Department of Cardiology, Huddinge University Hospital, Karolinska Institute, Sweden

Competing interests: none declared

\section{REFERENCES}

1 Horsburgh CR. Healing by design. N Engl J Med 1995;333:735-40

2 Rubin HR, Owens AJ, Golden G. Status report: an investigation to determine whether the built environment affects patients' medical outcomes. Martinez, CA: The Center for Health Design, 1998.

3 Ulrich RS. View through a window may influence recovery from surgery. Science 1984;224:420-1.

4 Ulrich RS. Effects of health facility interior design on wellness: theory and scientific research. Journal of Health Care Design 1991:3:97-109.

5 Ulrich RS, Zimring C. The role of the physical environment in the hospital of the 21 st century, The Robert Wood Johnson Foundation and the Center for Health Design.www.rwfi.org.

6 IOM (Institute of Medicine). Keeping patients safe: transforming the work environment of nurses. Washington, DC: National Academy Press, 2004.

7 Babwin D. Building boom. Hospitals \& Health Networks 2002;76(3):48-54.

8 Berglund B, Lindvall T, Schwela DH. Guidelines for community noise. Protection of the human environment. World Health Organisation, 1999.

9 McLaughlin A, McLaughlin B, Elliot J, et al. Noise levels in a cardiac surgical intensive care unit: a preliminary study conducted in secret. Intensive Crit Care Nurs 1996;12:226-30.

10 Hilton BA. Noise in acute patient care areas. Res Nurs Health 1985;8:283-91.

11 Redding JS, Hargest TS, Minsky SH. How noisy is intensive care? Crit Care Med 1977;5:275-6.

12 Baker CF, Garvin BJ, Kennedy CW, et al. The effect of environmental sound and communication on CCU patients' heart rate and blood rate and blood pressure. Res Nurs Health 1993;16:415-21.

13 Yinnon AM, Ilan Y, Tadmor B, et al. Quality of sleep in the medical department. Br J Clin Pract 1992;46:88-91.

14 Berg S. Impact of reduced reverberation time on sound-induced arousals during sleep. Sleep 2001;24:289-92.

15 Bayo MV, Garcia AM, Garcia A. Noise levels in an urban hospital and workers' subjective responses. Arch Environ Health 1995;50:247-51.

16 Norbeck J. Perceived job stress, job satisfaction, and psychological symptoms in critical care nursing. Res Nurs Health 1985;8:97-122.

17 Topf M, Dillon E. Noise-induced stress as a predictor of burnout in critical care nurses. Heart Lung 1988;17:567-573.

18 Evans GW, Cohen S. Environmental stress. In: Stokols D, Altman I, eds. Handbook of environmental psychology. New York: John Wiley, 1987:571-610.

19 Parsons R, Hartig T. Environmental psychophysiology. In: Caccioppo JT, Tassinary LG, Berntson G, eds. Handbook of psychophysiology. New York: Cambridge University Press, 2000:815-46.
20 Lundberg M, Frankenhaeuser M. Psychophysiological reactions to noise as modified by personal control over noise intensity. Biol Psychol 1978:6:51-9.

21 Jones D, Broadbent DE. Side effects of interference with speech by noise. Ergonomics 1979;22:1073-81.

22 McLaughlin A, McLaughlin B, Elliot J, et al. Noise levels in cardiac surgical intensive care unit; a preliminary study conducted in secret. Intensive Crit Care Nurs 1996;12:226-30.

23 Baker CF. Discomfort to environmental noise: heart rate responses of SICU patients. Crit Care Nurs Q 1992;15(2):75-90.

24 Karasek RA, Theorell T. Healthy work: stress, productivity, and the reconstruction of work life. New York: Basic Books, 1990.

25 Topf M. A framework for research on aversive physical aspects of the environment. Res Nurs Health 1984;7:35-42.

26 Schnall $P$, Belkic K, Landbergis $P$, et al. The workplace and cardiovascular disease. In: Occupational medicine. Hanley \& Belfus, 2000:183-8.

27 Bongers PM, de Winter CR, Kompier MAJ, et al. Psychosocial factors at work and musculoskeletal disease. Scand J Work Environ Health 1993;20:73-86.

28 Theorell T, Hasselhorn HM, Vingård E, Andersson B, the MUSIC-Norrtälje group study group. Interleukin 6 and cortisol in acute musculoskeletal disorders: results: results from a case-referent study in Sweden. Stress Med 2000;16:27-35.

29 Arnetz BB. Staff perception of the impact of health care transformation on quality of care. Int J Qual Health Care 1999;11:345-51.

30 Cronqvist A, Theorell T, Burns T, et al. Dissonant imperatives in nursing: a conceptualization of stress in intensive care in Sweden. Intensive Crit Care Nurs 2001;17:228-36.

31 Nabelek AK, Nabelek I. Room acoustics and speech perception. In: Katz J, eds. Handbook of clinical audiology, 4th edn. Baltimore: Williams and Wilkins, 1994.

32 Topf $M$. Hospital noise pollution: and environmental stress model to guide research and clinical interventions. J Adv Nurs 2000;31:520-8.

33 Karasek AK. Job demands, job decision latitude, and mental strain: implications for job redesign. Adm Sci Q 1979;24:285-308.

34 Shimomitsu T, Theorell T. Intraindividual relationships between blood pressure level and emotional state. Psychother Psychosom 1996;65:137-44.

35 Gillberg M, Kecklund G, Åkerstedt T. Relations between performance and subjective ratings of sleepiness during a night awake. Sleep 1994:17:236-41.

36 ISO. Acoustics-measurement of reverberation time in auditoria. International Standard ISO 3382: 1975 3382, 1997. Geneva, Switzerland: International Organisation for Standardisation, 1975, 1997.

37 ISO. Acoustics-recommended practice for the design of low-noise workplaces containing machinery. Part 1: Noise control strategies. International Standard ISO 11690-1: 1996, Geneva, Switzerland: International Organisation for Standardisation, 1996.

38 ISO. Acoustics-recommended practice for the design of low-noise workplaces containing machinery. Part 2: Noise control measures. International Standard ISO 11690-2: 1996, Geneva, Switzerland: International Organisation for Standardisation, 1996.

39 ISO. Acoustics-recommended practice for the design of low-noise workplaces containing machinery. Part 3: Sound propagation and noise prediction in workrooms. International Standard ISO 11690-3: 1996, Geneva, Switzerland: International Organisation for Standardisation, 1996

40 IEC. Sound system equipment. Part 16: Objective rating of speech intelligibility by speech transmission index. International Standard IEC Publication 6026816: 1998, Geneva, Switzerland: International Electrotechnical Commission, 1998 .

41 ISO. Acoustics-measurement of sound absorption in a reverberation room International Standard ISO 354: 1985, Geneva, Switzerland: Internationa Organisation for Standardisation, 1985.

42 ISO. Acoustics-sound absorbers for use in buildings. Rating of sound absorption. International Standard ISO 11654: 1997, Geneva, Switzerland. International Organisation for Standardisation, 1997.

43 Morrison WE, Haas EC, Shaffner DH, et al. Noise, stress, and annoyance in a pediatric intensive care unit. Crit Care Med 2003;31:113-19. 